\title{
Sayısal Belediyecilik: Türkiye'deki Belediyelerin Yeni Medya Kullanımları
}

\author{
Nilüfer Pınar Kılıç (Arş. Gör. Dr.) \\ Ankara Üniversitesi İletişim Fakültesi \\ npkilic@ankara.edu.tr
}

Ergin Şafak Dikmen (Dr. Öğr. Üyesi)

iD Ankara Üniversitesi İletişim Fakültesi

sdikmen@ankara.edu.tr

Başvuru Tarihi: 13.03.2021

Yayına Kabul Tarihi: 11.04.2021

Yayınlanma Tarihi: 30.07.2021

https://doi.org/10.17680/erciyesiletisim.896129

\section{Öz}

Türkiye'de faaliyet gösteren belediyelerin web sitesi ve sosyal medya kullanımlarını tespit etmeyi amaçlayan çalışmada tam örnekleme yapılarak 81 il ve 919 ilçe belediyesinin web siteleri, Facebook, Twitter, Instagram ve YouTube hesapları incelenmiştir. Sayısal ortamın devingen olması nedeniyle web hasatçılı̆̆ı yöntemi kullanılarak 10-27 Mart 2020 tarihleri arasında belediyelerin internet siteleri ve sosyal medya hesapları kayıtlanmıştır. Kayıtlanan veriler kodlanarak nicel analize tabii tutulmuştur. Araştırmada bin belediyenin 932 tanesinin web sitesinin işler olduğu tespit edilmiştir. Web sayfalarının sosyal medya ile ilişkilendirilmesinde sorunlar olduğu gözlenmiştir. Buna göre web sitelerinde sosyal medya hesaplarına yönlendiren butonların hepsinin yönlendirme yapmadığı, bazılarının eski hesaplara ya da belediye başkanlarının kişisel hesabına yönlendirdiği, bazılarının ise kapatılan sosyal ağlara ait olduğu tespit edilmiștir. $\mathrm{Bu}$ durum belediyelerin web sitelerinin ağ yapılanmasının güncellenmediğini göstermektedir. Belediyelerin sosyal medya kullanım pratiklerine bakıldığında 944 belediyenin Facebook, 804 belediyenin Twitter, 729 belediyenin Instagram hesabı, 665 belediyenin ise YouTube kanalı olduğu belirlenmiştir. Ancak bazı belediyelerde sadece hesap alındığı, sosyal medya hesaplarının önemli bir kısmının paylaşım ve takipçi sayılarının az olduğu ve dolayısıyla etkin biçimde kullanılmadığı görülmüştür. En etkin sosyal medya hesaplarının çoğunlukla ilçe belediyelerine ait olduğunun tespit edildiği araştırmada sosyal medya hesaplarının kullanım süresi, paylaşım sayıları, takipçi sayıları ve belediyelerin nüfusları arasında doğrusal bir ilişki olmadığı söylenebilir.

Anahtar Kelimeler: İletişim, Belediye, Yeni Medya, Sosyal Medya, Web Sitesi, Yerel Yönetimler.

\footnotetext{
* Bu çalışma Ankara Üniversitesi İletişim Fakültesi NETlab Yeni Medya Araştırmaları Laboratuvarında yürütülmüştür. Kodlama sürecindeki katkılarından dolayı Görkem Baydar’a ve Fatma Kübra Şahin'e teşekkür ederiz.

Makalede yer alan görseller için web adresi: https://netlab.media/publication/belediye-yeni-medya
} 


\title{
Digital Municipalism: New Media Use of Municipalities in Turkey
}

\author{
Nilüfer Pınar Kılıç (Res. Asst. Ph.D.) \\ iD Ankara University Faculty of Communication \\ npkilic@ankara.edu.tr \\ Ergin Şafak Dikmen (Asst. Prof. Dr.) \\ D Ankara University Faculty of Communication \\ sdikmen@ankara.edu.tr
}

Date Received: 13.03.2021

Date Accepted: 11.04.2021

Date Published: 30.07.2021

https://doi.org/10.17680/erciyesiletisim.896129

\section{Abstract}

This study aims to identify the content management strategies of municipality's website and social media platforms in Turkey. In this context full sampling analysis was conducted by focusing on web sites, Facebook, Twitter, Instagram and YouTube accounts of 81 provincial and 919 district municipalities. These platforms of municipalities were registered between 10-27 March 2020 using the web harvesting method and afterwards were coded and subjected to quantitative analysis. In the research, it was found that 932 websites of one thousand municipalities are active. However, the findings show that the networking of municipal websites is not updated. Furthermore, it is determined that 944 municipalities have Facebook, 804 municipalities have Twitter, 729 municipalities have Instagram accounts, and 665 municipalities have YouTube channels. However, it has been observed that some municipalities have only signed up in a social media account but not used it effectively, most social media accounts have fewer post and followers. It can be said that there is no direct correlation between the duration of use of social media accounts, the number of shares, the number of followers and the population of the municipalities.

Keywords: Communication, Municipality, New Media, Social Media, Website, Local Governments. 


\section{Giriş}

Elektronik devlet (e-Devlet) altyapısına ilişkin adımların atıldığı 1990’lı yıllardan günümüze kadar geçen zamanda Türkiye'de kamu kurumları tarafından verilen kamusal hizmetlerin planlanması, karar verilmesi, uygulanması ve vatandaşa iletilmesi gibi birçok aşamada sayısal teknolojiler kullanılmıştır. Yerel halkın ihtiyaçlarını yerinde tespit ederek hizmet üreten belediyeler de bu dönüşümde yerini almış, su ve kanalizasyon gibi hizmetlere yönelik borç sorgulama ve ödeme, arsa metrekare birim değeri sorgulama, nöbetçi eczane, vefat, beyan, sicil, tahakkuk gibi bilgiler internet üzerinden sorgulanabilir hale gelmiştir. Yaklaşık otuz yılda ivmelenerek artan sayısal dönüşüm sürecini, belediyelerin web siteleri sahipliği üzerinden anlamak mümkündür: Örneğin 1999 yılında büyükşehir, il ve ilçe belediyelerinin web sitesi sahipliği 30 iken bu sayı 2009 yılında 973'e çıkmıştır (Kabakuş, 2010, s. 63). Sayısal teknolojilerin kullanılmasına ilişkin günümüzdeki durumu tespit etmek amacıyla tasarlanan çalışma Türkiye'deki belediyelerin kurumsal yeni medya platformlarının kullanımlarına odaklanmaktadır.

Belediyelerin yeni medya kullanım pratikleri yönetim ya da iletişim bağlamında farklı yaklaşımlarla ele alınmıștır. Halkın e-belediye hakkındaki bilgi düzeyine (Gürler Hazman, 2005), belediye başkanının sosyal ağ hesaplarına (Çalıșır, 2015), tek tek ya da karşılaştırmalı olarak il ve ilçe belediyelerinin sosyal medya kullanımlarına (Memiş, 2013); (Değerli, 2016); (Tarhan, 2012); (Solmaz \& Görkemli, 2012); (Sayılganoğlu, 2018); (Aydın, 2018), aynı şekilde il ve ilçe belediyelerinin web sitelerine (Karakurt Tosun, 2008); (Kaya \& Över, 2019); (Arıkboğa, 2017); (Özüpek, 2010); (Özüpek \& Altınbaş, 2012); (Yıldız İ. , 2019); (Yayınoğlu, Sayımer, \& Arda , 2007); (Kabakuş, 2010), yeni medya kullanımlarına (Şenyurt, 2015), ya da kamusal teşhir gibi sorun alanlarına (Yıldız M. , 2009) yönelik araştırmalar yapılmıştır. ${ }^{1}$ Bu çalışma hem Türkiye'deki bütün büyükşehir, il ve ilçe belediyelerinin tamamını bütüncül biçimde değerlendirmeye alması hem de bu kurumların web sitesi ve sosyal medya hesaplarının tamamını ele alması açısından diğer çalışmalardan farklılaşmaktadır.

Türkiye'de bulunan büyükşehir, il ve ilçe belediyelerinin web sitesi ve sosyal medya kullanımlarını ortaya çıkarmak amacıyla betimleyici olarak tasarlanan araştırmada Türkiye'de yer alan belediyelerin yeni medya ortamında nasıl bir dijital yapılanma izlediği, hangi çevrim içi platformları etkin biçimde kullandıklarıyla birlikte il, ilçe ve büyükşehir belediyelerinin kullandıkları platformlar ve içerik paylaşım düzeyleri açısından aralarında anlamlı bir farklılık bulunup bulunmadığı sorularına yanıt aranmıştır. Bu kapsamda Türkiye Belediyeler Birliği web sitesinde yer alan 30 büyükşehir, 51 il ve 919 ilçe belediyesinin web sitesi ve sosyal medya hesapları incelenmiştir.

\section{Yeni Medya Üzerine}

Günümüzde yeni medya kavramı sıklıkla kullanılan ve biraz da içi boşalan bir sözcük haline gelmiştir. İletişim teknolojileri üzerine 1960'lı yıllardan beri yürütülen tartışmalar 2000’li yıllardan itibaren internet teknolojisinin yaygınlaşmasıyla birlikte yeni medya başlığı altında devam etmiştir. Teknoloji ile ilişkili olarak gelişim gösteren medya (Yengin, 2014, s. 86), Lev Manovich'e göre (2001) medya teknolojilerinin bilgisayar ile yöndeșmesiyle yeni medyaya dönüşmüștür. Söz konusu yöndeşmeyle sayısal dilde kodlanabilir, hesaplanabilir, dönüștürülebilir, işlemlerin otomatik olarak yapılabildiği içeriklerin yer aldığı bir mecra bütünü ortaya çıkmıştır. Bu anlamda radyo ve televizyon gibi geleneksel medyadan farklı olarak sayısal tabanlı yeni medya platformları büyük miktardaki enformasyonun eş anlı aktarılmasının mümkün olduğu, kullanıcının 
anında yanıt verebildiği ve çok katmanlı etkileşimin gerçekleşebildiği bir ortam olarak karşımıza çıkmaktadır. Parçaların üzerinde ayrı ayrı değişiklik yapılabilmesine olanak tanıyan modüler yapıdaki yeni medyanın çoklu ortam (multimedia) biçimselliği ile "telekomünikasyon, veri iletimi, kitle iletişimi gibi iletişimin farklı boyutları ile imge, ses, metin ve sayısal veri gibi farklı veri türlerinin bir arada" bulunabilmesi (Binark, 2007, s. 21) mümkün olmaktadır.

Yeni medya teknolojilerinin önemli bir parçası haline gelen internet birbirine bağlanmış milyonlarca bilgisayardan oluşan küresel bir ăg yapısıdır. $\mathrm{Bu}$ ağ yapısında bulunan internet sitelerinin içeriklerini düzenleyerek kullanıcılar için küresel çapta bilgi kaynakları olușturmak mümkündür. Günümüzde internet statik yapıya sahip, metne dayalı yani sadece okumaya elverișli sayfaların bulunduğu tek yönlü bilgi aktarımının mümkün olduğu Web 1.0 (1990'lı yıllar) döneminden farklı bir boyut kazanmıștır (Güçdemir, 2015, s. 24-31). Bilgiye erişimin ardından 2000'li yıllarda kullanıcıların içerik üretebildiği Web 2.0. döneminde web etkileşimli bir sosyal ortama dönüşmüştür. Web 3.0. olarak adlandırılan 2010 sonrası dönemde ise büyük veri anlamsal olarak birbirleriyle ilişkilenmekte ve işlenmektedir (Yengin, 2014, s. 118-119).

Kullanıcıların içerik üretebildikleri günümüzde sosyal ağ siteleri, bloglar, içerik toplulukları, sanal dünyalar gibi farklı özelliklere sahip platformlarla etkileşim kurulabilmekte, kullanıcıların yanı sıra nesnelerin birbirine bağlanması mümkün hale gelmektedir. Bu yeni boyutta Facebook gibi sosyal paylaşım ağları, Instagram ve YouTube gibi fotoğraf ya da video paylașımı için geliștirilen platformlar, Myspace, Blogger gibi kullanıcıların kronolojik sırayla içerik yayınladıkları bloglar, Twitter gibi kısa ağ günceleri ya da mikrobloglar, Second Life gibi sanal yaşam ortamları, dijital ses kayıtlarının dağıtımını mümkün kılan podcastler, içerik besleme yöntemi olarak ifade edebileceğimiz Zengin Site Özeti (RSS; Real Simple Syndication veya Rich Sita Summary) gibi birçok sosyal medya platformundan söz etmek mümkündür (Güçdemir, 2015, s. 37-49); (Gönenli \& Hürmeriç, 2012, s. 216-218). Bu çerçevede kullanıcıların internet ortamında pek çok farklı platformu yoğun biçimde kullanması, özel şirketlerin olduğu kadar kamu kurum ve kuruluşlarının da kurumsal web sayfalarını ve sosyal medya hesaplarını etkin biçimde kullanmasını zorunlu kılmaktadır.

\section{Sayısal Belediyecilik}

Belediyeler kendi sınırları içerisinde yaşayan insan ve diğer canlıların yerel nitelikteki ihtiyaçlarının giderilmesi amacıyla oluşturulmuş anayasal kuruluşlardır. Kamu tüzel kişiliği niteliğinde olan belediyelerin görev ve yetkileri yasalarla belirlenmiștir ve karar organları seçimle göreve getirilmektedir. İdarî ve malî özerkliğe sahip belediyeler hayatımızın çeşitli yönlerini kapsayan hizmetleri yürütmektedirler (Özüpek, 2013, s. 2829); (Dikme, 2012, s. 92); (Belediye Kanunu, 2005). Belediye Kanunu'nda belediyelerin görev ve sorumlulukları arasında "imar, su ve kanalizasyon, ulaşım gibi kentsel altyapı", "çevre ve çevre sağlığı, temizlik ve katı atık”, "defin ve mezarlıklar", "park ve yeşil alanlar", "kültür ve sanat, turizm ve tanıtım," "öğrenci yurtları", "sosyal hizmet ve yardım", "nikâh", "meslek ve beceri kazandırma” (Belediye Kanunu, 2005) gibi birçok hizmet yer almaktadır.

Görev ve yetkileri bu kadar geniş kapsamlı olan belediyelerin birçok konuda halk ile doğrudan ilişki içerisinde olduğu söylenebilir. Karar organlarının seçimle göreve getirilmesi ve ihtiyaçların hangi öncelikle, kim tarafından ve nasıl giderileceği gibi kararların alınması gerekliliği nedeniyle belediyelerin siyasal ve yönetsel bir yönü 
bulunmaktadır. Ekonomik anlamda da şirket kurulabilen ve halkın denetim ve gözetimi altında hizmetlerini yürüten belediyeler (Özüpek, 2013, s. 28) halkla doğrudan iletişim kurabilmek, hizmetlerini daha hızlı, güvenilir ve kolay yürütebilmek amacıyla sayısal teknolojileri kullanmaya başlamışlar, 2000'li yılların başından itibaren hizmet sunumlarını elektronik ortama taşımışlardır (Pektaş, 2011, s. 70). Hatta bu süreçte Türkiye Cumhuriyeti İçişleri Bakanlığı Bilgi İşlem Dairesi Başkanlığı tarafından dijital dönüşümün yerel ağı kapsamında e-Belediye projesi yürütülmüştür. Proje kapsamında oluşturulan e-Belediye bilgi sistemi kapsamında elektronik belge, ruhsat bilgi sistemi, sosyal yardım takip sistemi, analitik muhasebe, bütçe gibi birçok alanda belgeler anlık olarak belediyelerle paylaşılmakta ve sisteme dahil olan belediyeler tarafından hızlı, güvenli ve kesintisiz hizmet verilmektedir (e-Belediye, 2018).

Yeni medya platformları belediyelerin sundukları hizmete yönelik fayda sağlamasının yanı sıra platformların iletişimsel ihtiyaçlar, demokrasi ve katılıma yönelik faydaları da bulunmaktadır. Örneğin yeni medya platformları ulaşım, su ve kanalizasyon gibi hizmetlerin planlanmasında ve sorunların tespitinde veri sağlayarak yönetsel kararların alınmasına destek olabilir (Pektaş, 2011, s. 68). Politika oluşturmaya ve hizmet sunumunu iyileştirmeye yardımcı olmak (Bonsón, Torres, Royo, \& Flores, 2012, s. 125) ya da sorunları tespit etmek amacıyla yürütülecek kamuoyu araștırmaları yeni medya kanalıyla daha hızlı, düşük maliyetli ve etkin yürütülebilir. Bununla birlikte yeni medyanın etkin kullanımı ile kamu yönetimine halkın katılımı artırılabilir ve şeffaflık sağlanabilir (Lovari \& Parisi, 2015, s. 206). Yeni medya, sosyo-politik tartışmaları zenginleştiren özgür bilgi akışını ve ifade özgürlüğünü artıran şekilde kullanılabilir (Bonsón, Torres, Royo, \& Flores, 2012, s. 124). Ayrıca yeni medya anlık bilgi sağlanmasına olanak veren yapısıyla, gerçek zamanlı bir iletişim kanalı olarak kullanılabilir. Böylece kriz ya da afet durumlarını yönetmede stratejik olarak kullanılabilir (Lovari \& Parisi, 2015, s. 206). Halkla ilişkiler ya da iletişim perspektifinden bakıldığında iki yönlü iletişime izin veren yeni medya ile halk ile belediye arasında resmi dil dışında samimi iletişim ve doğrudan etkileșim kurma olanağı sağlar. Ayrıca belediye ve farklı kamu kurumları, sivil toplum kuruluşları, okul ve hastane gibi kurumlar arasındaki işbirliğinin geliştirilmesine destek verebilir (Tarhan, 2012, s. 85); (Lovari \& Parisi, 2015, s. 206). Hedef kamuya yönelik uygun platform seçiminin yapılabileceği yeni medya ile hizmetlerin tanıtımı yapılabilir. Böylece bir yandan vatandaşların farkındalığı artırılarak hizmetlere erişim kolay hale gelebilir, diğer yandan da seçimle gelen karar organları meşruiyetini sağlayabilir.

Belediyeler açısından yeni medya sunduğu olanakların yanı sıra gizlilik ve kişisel verilerin korunması gibi bazı riskleri de beraberinde getirmektedir (Lovari \& Parisi, 2015, s. 206). Ayrıca uygulamada web sayfalarının etkileşime değil de tanıtıma yönelik tasarlanması, sık sık güncellenmemesi, bürokratik engeller, uzman ya da teknik personel eksikliği gibi (Pektaş, 2011, s. 75); (Karakurt Tosun, 2008, s. 77-78) çeşitli sorunlarla karşılaşılmaktadır.

\section{Yöntem}

Çalışmanın temel amacı Türkiye'de bulunan büyükşehir, il ve ilçe belediyelerinin web sitesi ve sosyal medya kullanımlarını ortaya çıkarmak ve uygulamalardaki olumlu ve olumsuz yönleri tartışmaktır. Belediyelerin yeni medya ortamında nasıl bir sayısal yapılanma izlediği, hangi çevrim içi platformları etkin biçimde kullandıkları; büyükşehir, il ve ilçe belediyelerinin kullandıkları platformlar ve içerik paylaşım düzeyleri açısından aralarında anlamlı bir farklılık bulunup bulunmadığı sorularına yanıt arayan araştırmada web siteleri üzerinden yürütülen e-tahsilat, e-beyan, mezarlık bilgi sistemi gibi hizmetler araştırma kapsamının dışında bırakılmıştır. 
Araştırmanın evrenini Türkiye'de faaliyet gösteren büyükşehir, il ve ilçe belediyeleri oluşturmaktadır. Evrene Türkiye Belediyeler Birliği web sitesinde yer alan belediyeler listesinden ulaşılmıştır (Belediyeler, tarih yok). Bu kapsamda 30 tanesi büyükşehir olmak üzere toplamda 81 il ve $919^{2}$ ilçe belediyesinden oluşan evrenin tamamının ulașlabilir olması nedeniyle örneklem seçimi yapılmamış, tam örnekleme yapılarak bütün il ve ilçe belediyeleri analize dahil edilmiştir.

Verilerinin toplanması sürecinde ilk olarak 10-27 Mart 2020 tarihleri arasında bin belediyenin web sitesi ve sosyal medya hesapları kayıt altına alınmıştır. $\mathrm{Bu}$ aşamada sayısal platformların devingen olması ve bin belediyenin nicelik açısından fazla olması nedeniyle kayıtlama sürecinin mümkün olduğunca hızlı biçimde tamamlanmasına özen gösterilmiştir. Kayıtlama aşamasında Google Chrome web tarayıcısı ve "Full Page Screen Capture" eklentisi kullanılmıștır. Kayıtlama ile platformların anlık görüntüsü alınarak çevrim içi ortamdaki değişimlerden yalıtılarak sabitlenmesi sağlanmıştır. Böylece platformların belli bir tarihteki durumlarının sabitlenmesi, arşivlenmesi ve bunların kodlama aşamasında kullanılabilmesi mümkün olmuştur. Ardından kayıt altına alınan niceliksel veriler elektronik hesap tablosuna (Microsoft Excel) kodlanmıștır. Kodlanan veriler 24-28 Haziran 2020 tarihleri arasında kontrol edilmiş ve güvenilirliğin sağlanabilmesi için verilerin \%10’u yeniden girilerek karşılaştırma yapılmıştır.

Kayıtlama aşamasında web sitelerinin işler kabul edilmesi için erişilebilir olması esas alınmıştır. Bakım aşamasında, güncelleme yapılıyor gibi uyarıların yer aldığı web siteleri işler kabul edilmemiştir. Facebook, Twitter, Instagram hesaplarının güncel kabul edilmesi için son yedi gün içinde paylaşım yapmaları temel ölçüt olarak belirlenmiştir. YouTube platformunun içerik üretim sürecinin ve paylaşım sıklığının farklı olması ve/veya sadece canlı yayın özelliğinin kullanılması nedeniyle güncellik ölçütü aranmamış, kanal açılış tarihi, yüklenen video ve abone sayıları kayıtlanmıştır.

\section{Bulgular}

\section{Belediyelerin Web Sitelerine Ilişsin Bulgular}

Araştırma kapsamında bakılan büyükşehir, il ve ilçe belediyeleri arasında $964(\% 96,4)$ belediyenin "bel.tr" şeklinde bir alan adına sahip olduğu yani bir internet sitesinin olduğu tespit edilmiştir. Büyükşehir ve il belediyeleri arasında web sitesi olmayan belediye bulunmamaktadır. Alan adı bulunan $964(\% 96,4)$ belediye internet sitesinin 932 $(\% 96,7)$ tanesi işler durumdadır, kalan 32 (\%3,3) adreste web sitesinin güncellendiği, yapılandırıldığı yazmakta ya da hiç çalışmamaktadır (Şekil 1).

İncelenen belediyeler arasında Akçakent, Akkışla, Aksu (Isparta), Arpaçay, Bayramören, Beytüşşebap, Boğazkale, Çeltikçi, Çiçekdağı, Demirözü, Digor, Diyadin, Gölova, Göynücek, Hani, Hasköy, Hazro, Hocalar, Horasan, İbradı, Kızı̈ören, Kocaköy, Korkut, Koyulhisar, Nazımiye, Özvatan, Polateli, Pütürge, Saraykent, Sason, Şirvan, Tufanbeyli, Türkeli, Yayladere, Yedisu, Yenipazar belediyelerinin kayıtlama zamanında alan adları dahil internet sitelerinin bulunmadığı görülmüştür. İnternet sitesi olmayan belediyeler için ilgili ilçenin kaymakamlık sitesinin altında belediyeye ait adres, telefon gibi iletişim bilgilerine ulaşılabilmektedir. Kayıtlama tarihi itibariyle $932(\% 93,2)$ belediyenin web sitesi aktif olarak bulunsa da 24-28 Haziran tarihleri arasında yapılan kontrolde Aliağa, Ermenek, Devrekani, Hanönü, İhsangazi, Kofçaz, Kula, Ömerli, Özalp, Pütürge, Saray (Van) belediyelerinin web sitelerinin işler hale geldiği; Çiçekdağı, Gölova, Türkeli ve Yenipazar belediyelerinin web sitelerinin yayına alındığı belirlenmiştir. Yine bazı belediyelerin 
yeni sosyal medya hesabı açtığı ya da var olan hesabı aktif olarak kullanmaya başladığı görülmüştür. Ancak kayıtlama tarihi esas alındığı için bu veriler tabloya eklenmemiştir.

Belediyelerin web sitelerinde yer alan sosyal medya platformlarına yönlendiren butonlara bakıldığında işler olan $932(\% 93,2)$ belediye sitesinin $823(\% 88,3)$ tanesinde Facebook hesaplarına yönlendirme yapan buton olduğu tespit edilmiş, söz konusu butonların $637(\% 77,4)$ tanesinin aktif olarak yönlendirme yaptığı görülmüştür. Yine işler belediye sitelerinin $771(\% 82,7)$ tanesinde yer alan Twitter butonunun $527(\% 68,3)$ tanesinin yönlendirme yaptığı belirlenmiștir. İşler olan 932 belediye web sitesinin $505(\% 54,2)$ tanesinde Instagram hesabına yönlendirme yapan buton olduğu belirlenmiş ancak butonların 360 tanesinin $(\% 38,6)$ yönlendirme yaptığı saptanmıștır. İșler web siteleri arasında $465(\% 49,9)$ belediyenin web sitesinde bulunan YouTube kanalına yönlendirme butonunun 293 (\%63) tanesinin aktif olarak çalıștığı tespit edilmiștir (Şekil 1). Öte yandan belediyelerin web sitelerinin ve sosyal medya platformları arasındaki ağ yapılanmasının güncelliğine yönelik fikir verecek bir bulgu olarak 932 sitenin $89(\% 9,5)$ tanesinde RSS (Rich Site Summary ve Really Simple Syndication), 140 (\%15) tanesinde ise 2 Nisan 2019 tarihinde kapatılan G+ (Google Plus) butonu olduğu görülmüştür. RSS butonu olan 89 $(\% 9,5)$ belediye sitesini $66(\% 74,1)$ tanesi bağlantıya yönlendirme yapmakta iken, kalan $23(\% 25,8)$ buton çalışmamaktadır.

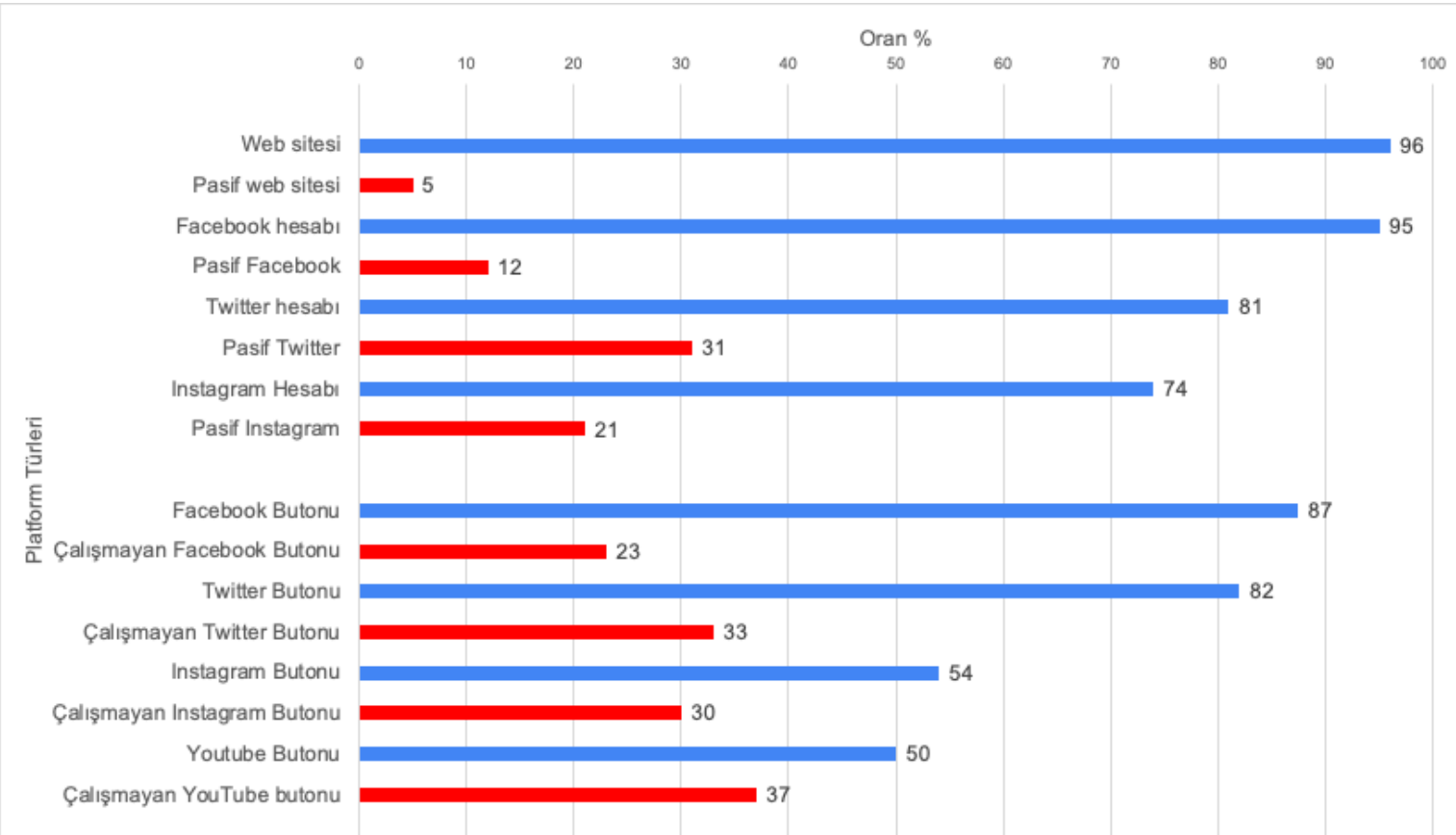

Şekil 1. Belediyelerin Platformlar Arası Geçişkenliği ve Etkinlik Durumu

Belediyelerin sosyal medya platformlarına yönlendiren işler butonları arasında 62 belediyenin en az bir sosyal medya hesabının (Facebook, Twitter, Instagram veya YouTube) kurumsal hesap yerine belediye başkanının kişisel hesabına yönlendirme yaptığı tespit edilmiştir [4 (\%1,4) YouTube, $31(\% 8,6)$ Instagram, $38(\% 7,2)$ Twittter, 42 $(\% 6,6)$ Facebook]. Bu durum genellikle ilçe belediyelerinde yaşansa da Ağrı (Facebook), Burdur (Facebook), Edirne (Instagram), Samsun (Facebook, Twitter, Instagram) ve Tokat (Instagram) il belediyelerinde de olduğu görülmüștür. Söz konusu bağlantıların kurumsal hesap yerine belediye başkanlarına bağlanmasının yanında bazı web sitelerinin ve sosyal medya platformları arasındaki ağ yapılanmasının güncellenmediği anlaşılmıştır. Örneğin kayıtlama tarihinde Bayat ve Tercan belediyelerinin web sitelerinde yer alan 
Facebook butonlarının görevde olan belediye başkanı yerine bir önceki dönemde görev yapmış olan belediye başkanının hesabına yönlendirme yaptığı tespit edilmiştir. Benzer şekilde İhsaniye ve Palu belediyelerinin web sitelerindeki Twitter butonu eski belediye başkanının kişisel hesabına (@sabancabukMHP, @PaluBldBsk) yönlendirmektedir. Mihalgazi Belediyesinin web sitesinde bulunan buton aktif paylaşım yapan Twitter hesabı (@TRmihalgazibel) yerine aktif olmayan bir hesaba (@MHALGAZBELEDYE) yönlendirmektedir. Balçova belediyesinde de benzer bir durum yaşanmakta, web sitesi aktif Twitter hesabına (@balcovabb) değil, askıya alınmış bir hesaba (@balcovabld) yönlendirmektedir. Kayıtlama zamanında Kahramankazan (@KahramankazanBl) ve Han (@BelediyeHan) belediyelerinin Twitter hesapları askıya alındığı için diğer verileri girilememiş ve bu nedenle yok kabul edilmiştir. Mihalıcçık belediyesinin web sitesindeki buton çalışsa da yönlendirdiği @mihaliccikbelediyesi hesabı bulunmamaktadır. Ula belediyesinin web sitesindeki buton ise hem aktif olmayan hem de kurumsal olmayan bir hesaba (@smailAkkaya19) yönlendirmektedir. Söz konusu hesap bilgileri aşağıdaki gibidir:

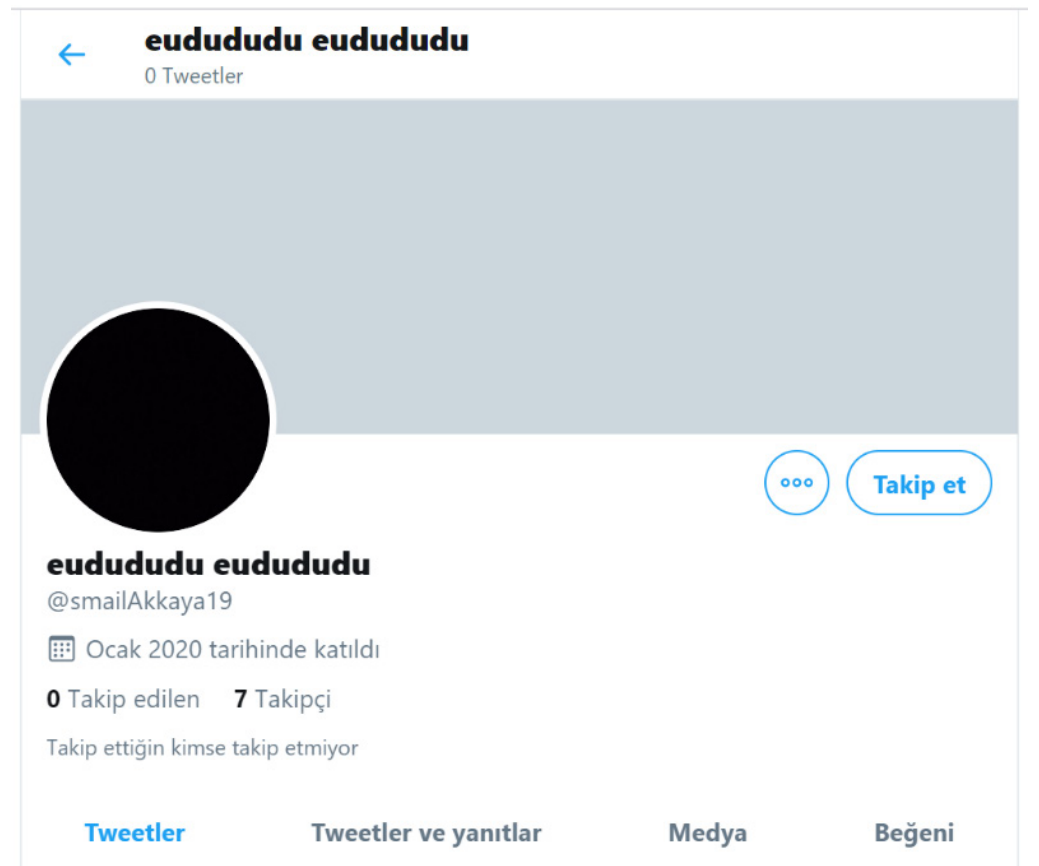

Şekil 2. Ula Belediyesinin Web Sitesindeki Twitter Butonunun Yönlendirdiği Hesap

Çalışma kapsamında ayrıca bazı belediyelerin web sitelerinde LinkedIn, Pinterest, web.tv, Vine gibi farklı platformlara yönlendirme yapan butonların olduğu tespit edilmiștir. Web sitesi işler olan $932(\% 93,2)$ belediye sitesinden 42 tanesinde $(\% 4,5)$ LinkedIn butonu bulunmaktadır. Ancak söz konusu butonlar ya hiç çalışmamakta ya da LinkedIn ana sayfasına yönlendirmektedir. LinkedIn butonu aktif olarak belediye hesabına yönlendiren iki tanedir: Kastamonu (https://www.linkedin.com/company/kastamonubelbsk/) ve Beşiktaş (https://www.linkedin.com/company/besiktas-belediyesi/). Ayrıca belediyelerin 24 tanesinin $(\% 2,5)$ web sitesinde Pinterest butonu olduğu belirlenmiştir. Söz konusu butonların üç tanesinin belediye hesabına yönlendirme yaptığı görülmüştür. Gölcük Belediyesinin web sitesinde Flickr, Bilecik ve Dazkırı Belediyelerinde web.tv, Nilüfer Belediyesinde Vine, Sultanhisar Belediyesinde Swarm, Buldan ve Nilüfer Belediyelerinde Foursquare, Altıeylül Belediyesinin web sitesinde canlıTV butonları olduğu tespit edilmiştir. 


\section{Belediyelerin Sosyal Medya Hesaplarına Yönelik Bulgular}

Belediyelerin sosyal medya hesaplarına bakıldığında (Şekil 1) $944(\% 94,4)$ belediyenin Facebook hesabının olduğu ve söz konusu hesapların $801(\% 84,8)$ tanesinin aktif olduğu yani son bir hafta içerisinde paylaşım yaptığı belirlenmiştir. Ancak Facebook platformu toplam paylaşım sayısını vermediği için belediyelerin ne kadar paylaşım yaptıklarını tespit etmek ya da karşılaştırma yapmak mümkün olmamıştır. Facebook platformuna üye olunma tarihlerine bakıldığında ise ilk hesabın Kepez Belediyesi tarafından 2007 yılında alındığı tespit edilmiştir. 2010 yılından itibaren sosyal medya platformlarında kurumsal hesap açılma sayısında artış görülmeye başlanmış, en çok hesap açılışı 2014 ve 2019 yıllarında gerçekleștirilmiştir (Şekil 3). Bunun yanı sıra belediyelerin Facebook hesaplarını farklı şekillerde açmaları nedeniyle takipçi sayılarını kıyaslamak mümkün olmamıştır. Başka bir ifadeyle bazı belediyelerin hesaplarını kurumsal olarak açmadıkları, kişi hesabı olarak açtıkları ve bu nedenle takipçi yerine arkadaş sayılarının olduğu görülmüştür.

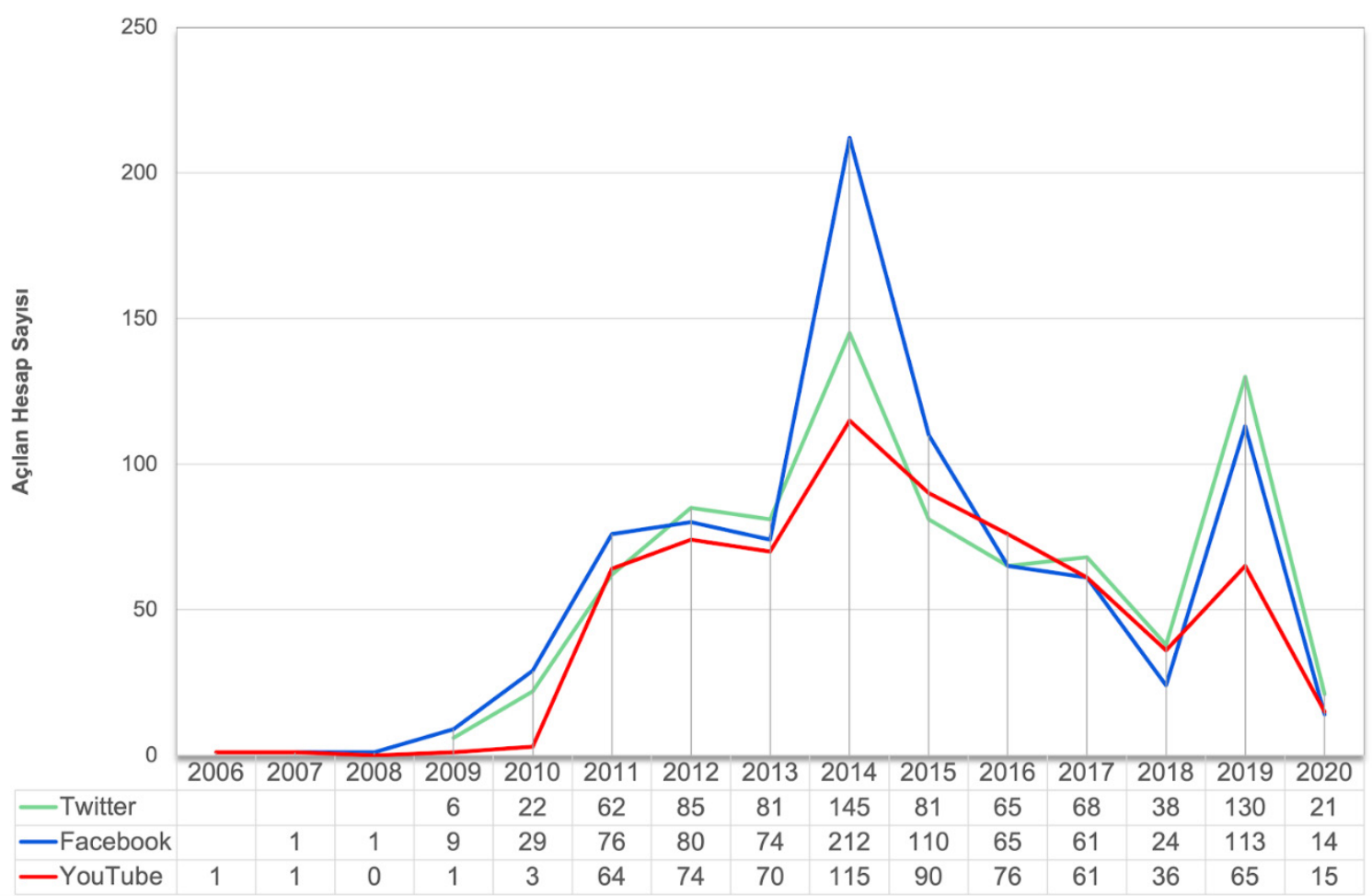

Şekil 3. Belediyelerin Sosyal Medya Hesaplarının Açılış Tarihleri

Araştırma kapsamında incelenen bin belediyenin $804(\% 80,4)$ tanesinin Twitter hesabı olduğu ve bunların $557(\% 65,2)$ tanesinin aktif olduğu tespit edilmiştir. Belediyelerin Twitter hesaplarının aktif olup olmamalarının belirlenmesi için son yedi günlük paylaşımlarına bakılmıștır. Twitter platformuna üye olunma tarihlerine bakıldığında 2009 yılında Altınyayla, Bursa Büyükşehir, Eyüp, Kartal, Karabük ve Meram belediyeleri tarafından ilk hesapların alındığı tespit edilmiştir. Facebook'la benzer şekilde 2010 yılından itibaren kurumsal hesap açılma sayısında artış yaşanmış ve en çok hesap açılıșının 2014 ve 2019 yıllarında olduğu görülmüștür (Şekil 3).

Paylaşımlara bakıldığında bazı belediyelerin sadece hesap adı aldıkları ve herhangi bir etkileşimde bulunmadıkları belirlenmiștir. Hesap adı olan 39 belediyenin $(\% 4,8)$ hiç Tweet'inin olmadığı yani hiç paylaşım yapmadığı, $116(\% 14,2)$ tanesinin paylaşım sayılarının on veya onun altında olduğu görülmüștür. Belediyelerin Twitter 
platformundaki paylaşımlarının belediyelerin platforma üye oldukları tarih ile orantılı olarak değişebileceği bilinmektedir. Örneğin $20(\% 2,49)$ belediyenin Twitter hesabı 2020 yılının ilk üç ayında açılmıştır. 2019 yılında 130 belediye $(\% 16,2)$ hesap açmıştır. En çok paylaşım yapan (Şekil 4) ilk on belediye olan Ataşehir, Çankaya, Kadıköy, Pendik, Esenler, Üsküdar, Fatih, Edremit, Maltepe, Ümraniye, Şanlıurfa ${ }^{3}$ belediyeleri 6-10 yıl arasında Twitter kullanmaktadırlar. Öte yandan platforma erken bir tarihte üye olmak da çok sayıda paylaşım yapmayı getirmemektedir. 2009-2015 yılları arasında 482 adet belediye Twitter hesabı açmıştır. Söz konusu belediyeler içerisinde yer alan $51(\% 10,6)$ belediyenin 10'dan az tweeti bulunmaktadır. Dolayısıyla yıl ve paylaşım sayıları arasında doğrusal bir ilişki olduğunu söylemek mümkün değildir.

Belediyelerin Twitter hesaplarının takipçi sayılarına bakıldığında 172 (\%21,4) belediyenin hesabının takipçi sayısı 100'ün altındadır. Takipçi sayısı 500'ün altında olan $368(\% 45,7)$ belediye, 1000'in altında olan $453(\% 56,3)$ belediye bulunmaktadır. 100 binin üzerinde takipçisi olan belediyeler Gaziantep, Nilüfer, Beşiktaş, Konya, Antalya, Bursa, İzmir, Ankara, İstanbul ve Kadıköy belediyeleridir. Takipçi sayısı milyonun üzerinde olan iki belediye bulunmaktadır: İstanbul (1,1 milyon) ve Kadıköy (2,1 milyon). Paylaşım ve takipçi sayıları yüksek olan belediyelerin büyükşehir olmadıkları düşünüldügünde nüfus ve etkileşim arasında da doğrusal bir ilişki olmadığını söylemek mümkündür.

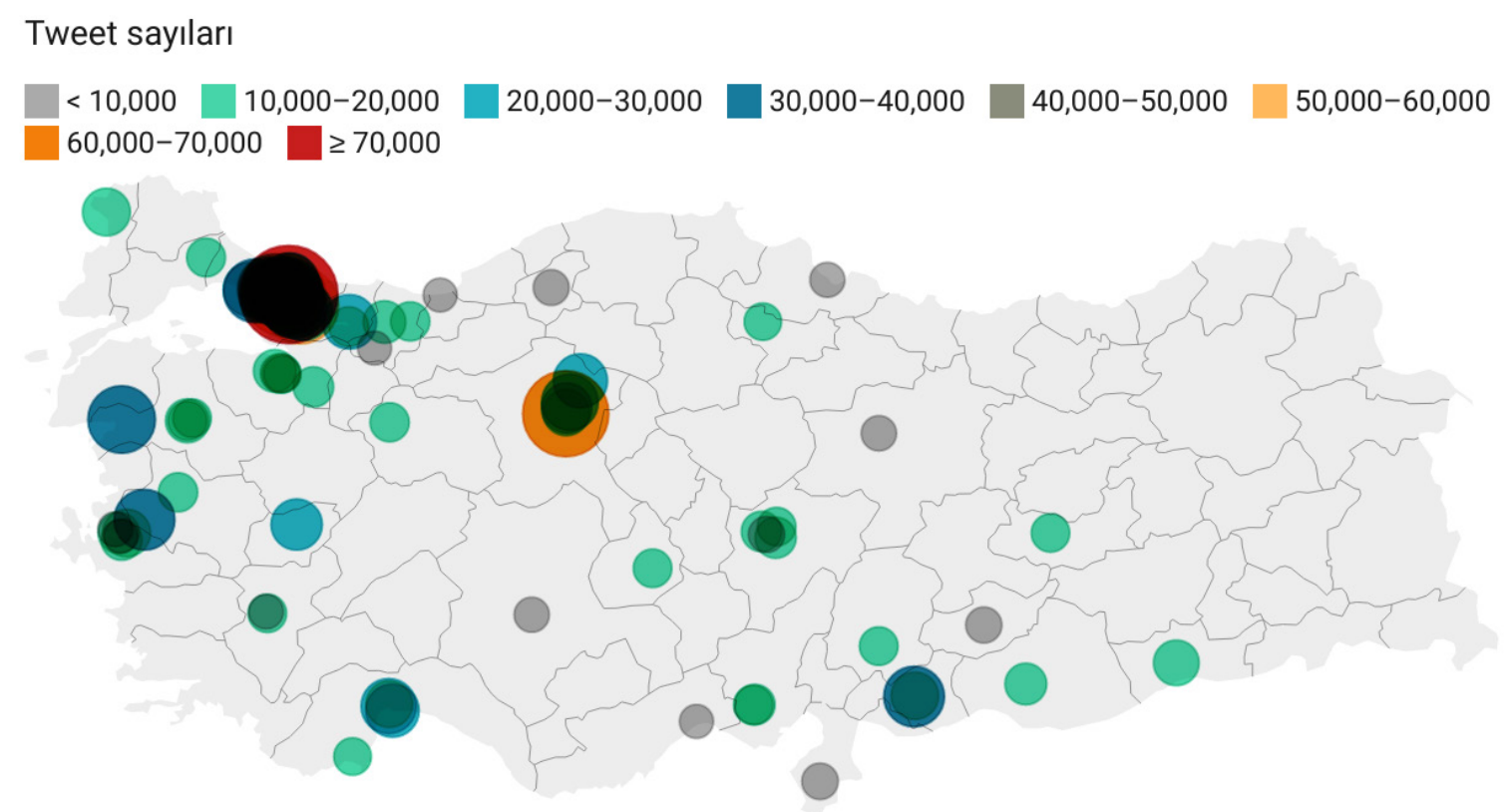

Created with Datawrapper

Şekil 4. Twitter'da En Çok Paylaşım Yapan 100 Belediyenin Tweet Sayıları (Coğrafi Konuma Göre)

Belediyelerin Instagram hesabına bakıldığında ise $729(\% 72,9)$ belediyenin hesabının olduğu ve bunların $575(\% 78,9)$ tanesinin aktif olduğu tespit edilmiştir. Twitter ile benzer şekilde belediyelerin Instagram hesaplarının aktif olup olmamalarının belirlenmesi için son 7 günlük paylașımlarına bakılmıştır. Burada da bazı belediyelerin sadece hesap adı aldıkları ve herhangi bir etkileşimde bulunmadıkları görülmüştür. $\mathrm{Bu}$ kapsamda hesap adı olan $40(\% 5,5)$ belediyenin hiç paylaşım yapmadığı, toplamda 84 $(\% 11,5)$ belediyenin ise 10 ve altında gönderisi olduğu tespit edilmiştir. En çok paylaşım yapan belediye Tuşba Belediyesidir. (https://www.instagram.com/tusbabeltr/; 12831 
paylaşım). En çok paylaşım yapan ilk 10 belediyeye bakıldığında Tuşba belediyesinin ardından Merzifon, Beylikdüzü, Haliliye, Sancaktepe, Pendik, Fatih, Çekmeköy, Adana ve Şanlıurfa gelmektedir. Takipçi sayılarına bakıldığında $36(\% 4,9)$ belediyenin takipçi sayısının 100'ün altında olduğu, $137(\% 18,8)$ belediyenin takipçi sayısının 500'ün altında, $269(\% 36,9)$ belediyenin takipçi sayısının 1000'in altında olduğu görülmüştür. Takipçi sayısı en yüksek belediyeler sırasıyla Kadıköy, İstanbul, İzmir, Ankara, Gaziantep, Antalya, Adana, Eskişehir, Beylikdüzü ve Mersin belediyeleridir. Mahmudiye ve Yenifakılı belediyelerinin hiç takipçisi yokken, Korkuteli, Ergani ve Keskin belediyelerinin takipçi sayısının 10’un altında olduğu tespit edilmiștir.

YouTube platformuna bakıldığında $665(\% 66,5)$ belediyenin bir YouTube kanalının olduğu tespit edilmiştir. Ancak YouTube platformunun paylaşım yapısının farklı olması nedeniyle hesapların aktiflik ya da pasiflikleri yerine video sayılarına bakılmıștır. Burada da yine bazı belediyelerin sadece kanal açtığı görülmüştür. $14(\% 2,1)$ belediyenin kanalında hiç video yokken $283(\% 42,5)$ belediyenin YouTube kanalında 10 ve daha az video yer almaktadır. Kanalında en çok video bulunan belediyeler: Manisa, Haliliye, Şanlıurfa, Mersin, Karabük, Karaköprü, Kocasinan, Antakya, Beyoğlu ve Adana'dır. Kanal aboneliklerine bakıldığında 21300 kişiyle İstanbul Büyükşehir Belediyesinin abone sayısının en fazla olduğu görülmektedir. Ardından Antalya, Etimesgut, Çankaya, Ankara, Diyarbakır, İzmir, Adana, Yıldırım belediyeleri gelmektedir. Şanlıurfa Belediyesinin abone sayısı kanalında görünmemektedir. Bu nedenle sıralamada yer almamıştır. Ancak video ve izlenme sayıları düşünüldügünde ilk on belediye arasında yer alabileceği değerlendirilmektedir. En az abonesi olan kanallara bakıldığında, 30 (\%4,5) belediyenin hiç abonesinin olmadığ, $172(\% 25,8)$ belediyenin ise 10 ve altında abonesinin olduğu tespit edilmiștir. $405(\% 60,9)$ belediye kanalının 100'ün altında abonesi varken, 568 $(\% 85,4)$ belediyenin 500 'ün altında abonesi bulunmaktadır.

Belediyelerin sosyal medya platformlarına ilişkin bulgularda ayrıca bazı belediyelerin birden çok hesabının olduğu tespit edilmiştir. Örneğin Döşemealtı, Kozan, Susurluk, Kozluk, Maden, Eğirdir, Tire belediyelerinin birden fazla Twitter, Ardanuç, Damal, Pazaryeri ve Ekinözü belediyelerinin birden fazla Facebook, Kaman ve Korkuteli belediyelerinin birden fazla Instagram hesaplarının olduğu belirlenmiştir.

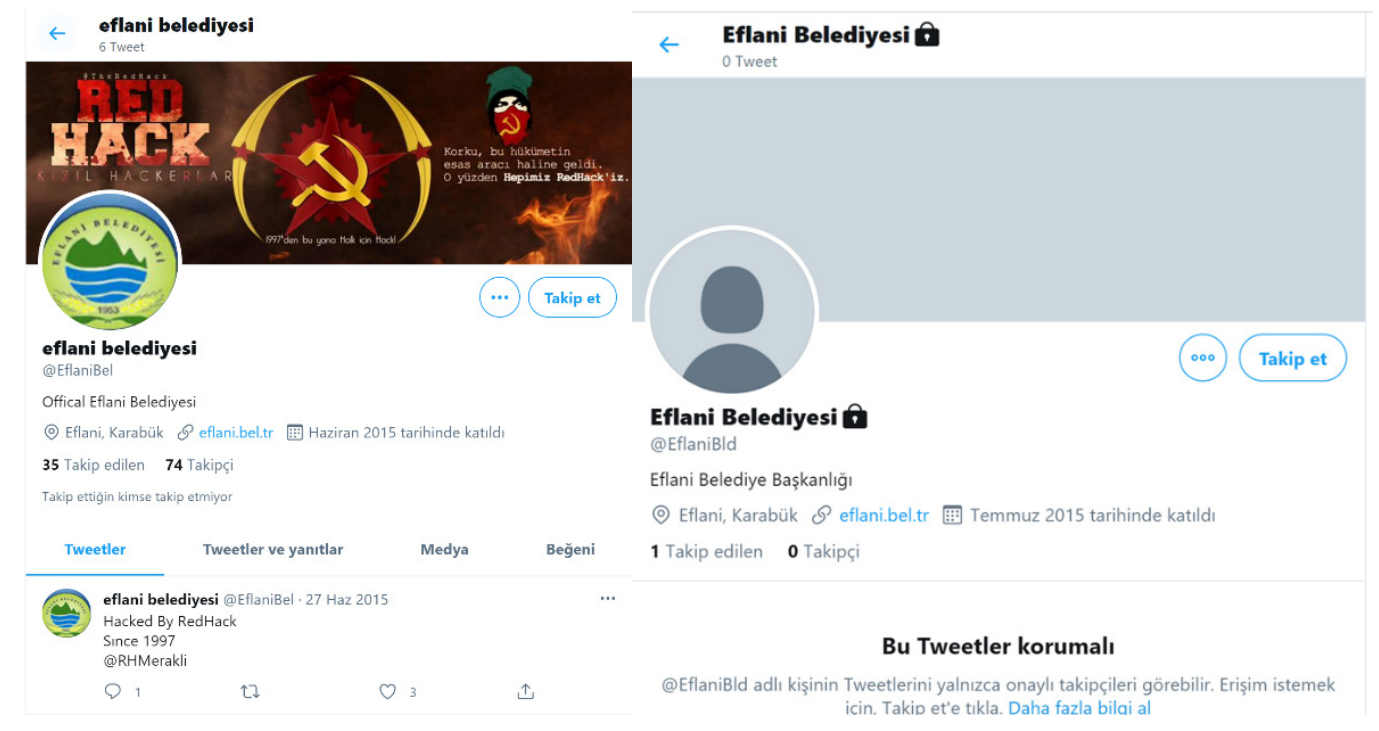

Şekil 5. Eflani Belediyesi Twitter Hesapları 
Belediyelerin sosyal medya hesaplarının ya da web sitelerinin güvenliği konusunda örnek teşkil edilebilecek bir bulgu olarak Eflani Belediyesi Twitter hesabı verilebilir. Kayıtlama zamanından belediyenin Haziran 2015 tarihinde açtığı Twitter hesabının (EflaniBel) bilgisayar korsanı tarafından erişime engellendiği görülmüştür (Şekil 5). Temmuz 2015 tarihinde açılan yeni hesabın ise (@EflaniBld) aktif olmadığı tespit edilmiştir.

\section{Sonuç ve Değerlendirme}

Türkiye'deki büyükşehir, il ve ilçe belediyelerinin yeni medya kullanımlarını ortaya çlkarmayı amaçlayan araştırmada incelenen bin belediyenin 932 (\%93,2) tanesinin web sitesinin işler olduğu görülmüștür. Büyükșehir ve il belediyelerinin tamamının web sitelerinin işler olduğu ortamda $68(6,8 \%)$ ilçe belediyesinin web sitesinin olmaması çevrim içi hizmet sunmadığına işaret etmektedir. İşler belediye web sitelerinde yer alan yönlendirme butonlarının tamamının yönlendirme yapmaması ya da pasif sosyal ağlara dair butonların olması ağ yapılanmasının güncellenmediğini göstermektedir. Örneğin Google'ın 28 Haziran 2011 tarihinde kullanıma açtığ sosyal ağ girişimi G+ (Google +) 2 Nisan 2019'da kullanıma kapatılmıștır. Kayıtlamanın yapıldığı Mart 2020 tarihine kadar aradan geçen 11 ayda en azından G+ butonu bulunan 140 (\%15) belediyenin web sitesinin ağ yapılanmasını güncellemediğini söylemek mümkündür. Artık faaliyet göstermeyen bir uygulamanın hala kurumsal bir sitede görünüyor olmasının getirdiği olumsuzluğun yanı sıra sosyal medya hesaplarına yönlendiren butonların tamamının belediyelerin işler kurumsal hesaplarına yönlendirmemesi web siteleri açısından bir diğer güncellenmeme sorunu olarak ele alınabilir. Bununla birlikte web sitelerinde yer alan butonların bazılarının eski belediye başkanının sosyal medya hesabına yönlendirmesi bir güncellenmeme sorunu olarak değerlendirilebilirken, görevdeki belediye başkanına yönlendirmesi de kurumsal iletişim açısından yanlış bir uygulamadır. Seçimle gelen belediye başkanlarının görev süreleri dolduğunda yerlerine bir başkasının geleceği düșünüldüğünde kurumsal bir tüzel kişilik olan belediyenin kendi hesabının olması ve sürdürebilirliğinin sağlanması önemlidir. Çoklu sosyal medya hesapları da bu açıdan değerlendirildiğinde belediye başkanı ya da birlikte çalışan ekibin değişmesiyle birlikte eski hesabın işlerliğinin korunamadığı ya da şifrelerine erişimin sağlanamadığı söylenebilir.

Belediyelerin sosyal medya platformları kullanımlarına bakıldığında bütün belediyelerin yer aldıkları platformlarda aktif paylașım yaptıklarını ve hemşerileriyle etkileşim kurduklarını söylemek mümkün değildir. Sosyal medya platformlarında hesapları bulunan belediyelerin 39 tanesinin hiç Twitter paylaşımı yapmadığı (ya da Tweet atmadığı), 40 tanesinin hiç Instagram gönderisi paylaşmadığı ve 14 tanesinin YouTube kanalında hiç videosu olmadığı düşünüldüğünde sadece hesap adı aldıkları söylenebilir. Bir sorun alanı olarak karşımıza çıkan bu durumda sadece kurumsal sosyal medya hesaplarının açılmasının yeterli olmadığı aynı zamanda sürdürebilirliğin de sağlanması için de planlama yapılması gerektiği söylenebilir. Öte yandan sosyal medya hesaplarının açılış tarihlerindeki pik yapma tarihlerine bakıldığında 2014 ve 2019 yıllarındaki seçim zamanlarına denk geldiği görülmektedir. Bu açıdan bu dönemde sosyal medya hesaplarının siyasal iletişim kapsamında kullanılabilmesi açısından da açıldığı değerlendirilebilir.

Genel olarak bakıldığında belediyelerin sosyal medya hesaplarındaki paylaşım sayılarının ve takipçi sayılarının az oluşu bütün belediyelerin sosyal medya platformlarını etkin olarak kullanmadıklarına ișaret etmektedir. Bununla birlikte belediyelerin sosyal medya hesaplarının açılış tarihi, nüfusları ve paylaşımları arasında doğrusal bir ilişki olduğunu söylemek mümkün değildir. Sonuç olarak belediyelerin web sitelerinin ve sosyal medya 
hesaplarının işlerliği, güncelliği ve sürdürebilirliği konusunda yaşadıkları sorunların tespit edilmesine yönelik araştırmaların yapılmasına gereksinim duyulmaktadır. Tüm yeni medya içeriğine yönelik analizlerde olduğu gibi bu çalışma da belli bir zamanda belediyelerin anlık görüntüsünü vermektedir. Devingen bir yapı olan ortamda elde edilen bulgular sürekli değişmektedir. Bu nedenle bu çalışmanın sonuçları bir durum tespiti niteliğindedir ve gelecekteki araştırmalarla bulguların güncellenmesi gerekmektedir. Ayrıca kamu kurumları ve halk arasındaki ilișkinin belirleyicisi teknoloji değil, teknolojiyi kullanma biçimidir. Bu nedenle belediyelerin web sitesini ya da sosyal medya platformlarını kullanıp kullanmadıklarının tespitinin yanı sıra nasıl kullandıkları da önem taşımaktadır. Sadece tanıtmaya yönelik tek yönlü, monolojik bir iletişim ile yeni medyanın etkileşim, katılım gibi olanaklarından yararlanmak mümkün değildir. Bu bağlamda çalışmanın genişletilerek, belediyelerin kamuyla yani hemşerilerle iletişim biçimlerinin içeriğinin analizine odaklanan yeni çalışmalara ihtiyaç duyulmaktadır.

\section{Notlar}

1 E-Belediyecilik ve belediye web sayfaları ile ilgili çalışmalara ilişkin literatür için (Mecek, 2017)'ye bakınız.

2 İçişleri Bakanlı̆̆ı IIller İdaresi Genel Müdürlüğü Ilçeler Genel Listesi'nde (Mülki İdare Birimleri, tarih yok) 922 ilçe belediyesi yer almaktadır. Söz konusu listede Türkiye Belediyeler Birliği web sitesinde belde olarak görülen Artvin Kemalpaşa, Hakkâri Derecik ve Zonguldak Kilimli belediyeleri ilçe olarak görünmektedir. Kayıtlama aşamasında Belediyeler Birliği listesi esas alındığı için adı geçen üç belediye listeye eklenmemiştir.

3 Ümraniye Belediyesinin ve Şanlıurfa Büyükşehir Belediyesinin tweet sayıları eşittir. İki belediye birlikte onuncu sıradadırlar.

\section{Kaynakça}

Arıkboğa, Ü. (2017). Belediye hizmetlerinin elektronik ortamda sunumu: İstanbul Büyükşehir Belediyesi e-Belediye uygulamalarının analizi. Süleyman Demirel Üniversitesi Íktisadi ve İdari Bilimler Fakültesi Dergisi, 22 (Kayfor15 Özel Sayısı), 1619-1644.

Aydın, M. P. (2018). Belediyelerde halkla ilişkiler aracı olarak sosyal medya kullanımı: Büyükşehir belediyelerinin Twitter hesapları üzerine bir inceleme. Marmara Üniversitesi Sosyal Bilimler Enstitüsü Yayımlanmamış Yüksek Lisans Tezi. İstanbul.

Belediye Капипu. (2005, 7 13). mevzuat.gov.tr: https://www.mevzuat.gov.tr/ MevzuatMetin/1.5.5393.pdf adresinden alındı

Belediyeler. (tarih yok). Mart 5, 2020 tarihinde Türkiye Belediyeler Birliği: https://www. tbb.gov.tr/belediyelerimiz/belediyeler/ adresinden alındı

Binark, M. (2007). Yeni medya çalışmalarında yeni sorular ve yöntem sorunu. M. Binark (Dü.) içinde, Yeni medya çalışmaları (s. 21-44). Ankara: Dipnot.

Bonsón, E., Torres, L., Royo, S., \& Flores, F. (2012). Local e-government 2.0: Social media and corporate transparency in municipalities. Government Information Quarterly, 123-132. doi:https://doi.org/10.1016/j.giq.2011.10.001

Çalışır, G. (2015). Halkla iliş̧kiler uygulaması olarak belediyelerde sosyal ağların kullanımı. Çağdaş Yerel Yönetimler, 24(4), 59-93.

Değerli, A. (2016). Ağ toplumunun iletişimi ekseninde yerel yönetimlerin sosyal medya kullanım düzeyi: Kadıköy Belediyesi örneği. Marmara Üniversitesi Öneri Dergisi, 12(46), 63-79. doi:10.14783/od.v12i46.1000010004

Dikme, H. (2012). Yerel yönetimlerde halkla ilişskiler uygulamaları. İstanbul: Yalın. 
e-Belediye. (2018, Ekim 1). icisleri.gov.tr: https://www.icisleri.gov.tr/bilgiislem/ebelediye-projesi adresinden alındı

Gönenli, G., \& Hürmeriç, P. (2012). Sosyal medya: Bir alan çalışması olarak Facebook kullanımı. T. Kara, \& E. Özgen (Dü) içinde, Sosyal medya akadem, (s. 213-242). İstanbul: Beta.

Güçdemir, Y. (2015). Sanal ortamda iletişim “Bir halkla ilişkiler perspektifi". İstanbul: Derin.

Gürler Hazman, G. (2005). Afyonkarahisar Belediyesinde e-Belediye uygulamaları ve yerel farkındalı. Afyon Kocatepe Üniversitesi, I.I.I.B.F. Dergisi, 65-84.

Kabakuş, A. K. (2010). Türkiye'deki belediye internet sitelerinin nicelik ve nitelik bakımından incelenmesi. Erzurum: Atatürk Üniversitesi Sosyal Bilimler Enstitüsü İşletme Anabilim Dalı Yayımlanmamış Yüksek Lisans Tezi.

Karakurt Tosun, E. (2008). Türkiye'de e-Belediyecilik uygulamaları: Bursa NilüferOsmangazi-Yıldırım Belediyelerinin web sitelerinin analizi. Çağdaş Yerel Yönetimler, 17(2), 71-94.

Kaya, T., \& Över, A. S. (2019). Bakanlık ve belediye web sitelerinin içerik analiz yöntemiyle e-Katılımcılık bağlamında incelenmesi: KKTC örneği. Atatürk Üniversitesi Íktisadi ve İdari Bilimler Dergisi, 33(4), 1201-1226.

Lovari, A., \& Parisi, L. (2015). Listening to digital publics. Investigating citizens' voices andengagement within Italian municipalities' Facebook Pages. Public Relations Review, 41(2015), 205-213.

Manovich, L. (2001). The Language of New Media. Cambridge, MA and London: The MIT Press.

Mecek, M. (2017). e-Devlet ve e-Belediye: Kavramsal çerçeve ve Türkiye'de belediye web sitelerine yönelik yapılan çalışmaların incelenmesi. Süleyman Demirel Üniversitesi İktisadi ve İdari Bilimler Fakültesi Dergisi, 22(Kayfor15 Özel Sayısı), 1815-1851.

Memiş, L. (2013). Yöneten-yönetilen etkileșiminin değişim aracı olarak sosyal ağlar: Belediye ve belediye başkanları Facebook ve Twitter kullanım örüntüsü. Yeni Medya Çalışmaları Kuram Medya Uygulama ve Siyasa I. Ulusal Kongresi (s. 601618). Kocaeli: Kocaeli Üniversitesi İletişim Fakültesi.

Mülki İdare Birimleri. (tarih yok). Haziran 20, 2020 tarihinde Türkiye Mülki İdare Bölümleri Envanteri: https://www.e-icisleri.gov.tr/Anasayfa/ MulkildariBolumleri.aspx adresinden alındı

Özüpek, M. N. (2010). Belediyelerin halkla ilişkiler çalışmalarında İnternet kullanımı: Büyükşehir belediyeleri web siteleri üzerine uygulamalı bir çalışma. Selçuk İletişim, 6(10), 196-205.

Özüpek, M. N. (2013). Belediyelerde halkla ilişkiler (2. b.). Konya: Eğitim.

Özüpek, M. N., \& Altınbaş, H. (2012). The aim of using websites in local governments for public relations. Yeni İletişim Teknolojileri ve Toplumsal Dönüşüm II. Uluslararası İletişim Sempozyumu, (s. 900-907). Manas.

Pektaş, E. K. (2011). Belediye hizmetlerinde bilgi-iletişim teknolojilerinin kullanımı ve e-belediye uygulamalarındaki son gelişmeler: Bir literatür taraması. Sosyal Bilimler Dergisi, XIII(1), 65-88. 
Sayllganoğlu, S. (2018). Kurumsal iletişim bağlamında belediyelerde kurumsal Twitter hesabı kullanımı. Çomü Uluslararası Sosyal Bilimler Dergisi, 3(2), 389-406.

Solmaz, B., \& Görkemli, H. (2012). Büyükşehir belediyeleri ve sosyal medya kullanımı. Akdeniz Üniversitesi İletişim Fakültesi Dergisi(18), 9-20.

Şenyurt, G. (2015). Belediyelerin halkla ilişkiler uygulamalarında internetin ve sosyal medyanın kullanımı: Konya merkez ilçe belediyeleri üzerine bir inceleme. İnönü Üniversitesi İletişim Fakültesi Elektronik Dergisi, 1(1), 44-67.

Tarhan, A. (2012). Büyükșehir belediyelerinin sosyal medya uygulamalarına halkla ilişkiler modellerinden bakmak. İletişim Kuram ve Araştırma Dergisi(35), 79-101.

Yayınoğlu, Y., Sayımer, Y., \& Arda , Z. (2007). Belediyelerin kurumsal web sitesi kullanımı üzerine bir inceleme: Londra Büyükşehir Yönetimi ve İstanbul Büyükşehir Belediyesi web sitesi ana sayfalarının karşılaştırılması. Galatasaray Üniversitesi İletişim Dergisi(7), 129-157.

Yengin, D. (2014). Yeni Medya ve Dokunmatik Toplum (2 b.). İstanbul: Derin.

Yıldız, İ. (2019). Belediyelerin iletişim çalışmaları kapsamında web sitesi kullanım durumları (Bingöl Belediyesi web sitesine yönelik bir içerik analizi). İstanbul Sosyal Bilimler Dergisi, 2019(Winter 23).

Yıldız, M. (2009). e-Devletin karanlık bir yüzü: Yerel yönetimlerde sanal kamusal teşhire ABD ve Türkiye'den birer örnek. Çağdaş Yerel Yönetimler, 18(3), 69-83. 


\title{
Digital Municipalism: New Media Use of Municipalities in Turkey
}

\author{
Nilüfer Pınar Kılıç (Res. Asst. Ph.D.) \\ Ergin Şafak Dikmen (Asst. Prof. Dr.)
}

\section{Extended Abstract}

This study aims to identify the content management strategies of municipality's web site and social media platforms in Turkey. Digital technologies are widely used in the planning of public services provided by institutions, decision, and application processes along with the transfer of information to public knowledge since the foundations of e-government infrastructure started in the early 1990s. In this sense, the feature of interaction is among the most important features of new media platforms; unlike traditional media such as radio and television, digital-based new media platforms, can transfer large amounts of information simultaneously.

New media platforms enable an environment where the user can respond instantly where a multi-layered interaction is created. The multimedia feature of new media refers to the coexistence of different dimensions of communication such as telecommunication, data transmission, mass communication and use of image, sound, text and digital data together. Today, the importance of municipalities and especially digital municipalities is increasing. In addition to providing benefits for the service offered by municipalities, new Media platforms provide opportunities for citizens in terms of effective communication, democracy and participation. The duties and powers of the municipalities are quite extensive, yet therefore, municipalities are in direct contact with the public on many issues. Municipalities have a political and administrative aspect due to the election of decision-making bodies where the necessity to make decisions such as the prioritization of the needs to be met. Since the beginning of the 2000s, municipalities have transferred their service provision to electronic environment for faster and more reliable services.

This research focuses on metropolitan, provincial and district municipalities. In this context, a sample from 30 metropolitan, 81 provincial and 919 district official web sites and social media accounts were collected and analysed by quantitative content analysis method. In the process of collecting data, the websites, and social media accounts of a thousand municipalities were first registered between 10-27 March 2020. At this stage, attention was paid to complete the registration process as quickly as possible, due to the dynamic nature of digital platforms and the large number of thousand municipalities.

In the research, it was determined that 932 out of one thousand municipalities were active. It has been observed that there are problems creating active links between municipalities web pages and their social media accounts. Accordingly, not all of the buttons redirecting to social media accounts on websites work, some refer to old accounts or the personal account of mayors, some were found to belong to closed social networks. This shows that the networking of municipal websites is not updated. Considering the social media usage practices of municipalities, it is determined that 944 municipalities have Facebook, 804 municipalities have Twitter, 729 municipalities have Instagram accounts, and 665 municipalities have YouTube channels. However, it has been observed that some municipalities have only opened accounts, the majority of social media accounts have 
fewer shares and followers, and therefore are not used effectively. It can be said that there is no linear relationship between the duration of use of social media accounts, the number of shares, the number of followers and the population of the municipalities in the study, in which the most effective social media accounts were found to be mostly owned by the district municipalities.

In Turkey, metropolitan, provincial and district municipalities examined in research aiming to reveal the use of new media thousand 932 municipalities (93.2\%) were not seen at the web construction jobs. The web server of 68 (6.8\%) municipalities where metropolitan and provincial municipal websites have become available indicates that they do not offer online services. Not all of the routing buttons on the municipality websites do not redirect or have passive social networks, the network is being made and is not updated.

Considering the use of social media platforms by municipalities, it is not possible to say that all municipalities actively share on the platforms they take place and interact with their fellow townsmen. On the other hand, when looking at the peak dates of social media accounts, it is seen that they coincide with the election times in 2014 and 2019. In this respect, it can be evaluated that social media accounts were opened in this period in terms of being used within the scope of political communication. In general, the low number of shares and followers in the social media accounts of the municipalities indicates that not all municipalities use social media platforms effectively. However, it is not possible to say that there is a linear relationship between the opening date of the social media accounts of the municipalities, their populations and their shares. In addition, the determinant of the relationship between public institutions and the society is not technology, but the way they use technology. For this reason, it is important for municipalities to use their website or social media platforms effectively and also the way that they use it. It is not possible to benefit from the opportunities such as interaction and participation of new media with a one-way, monological communication intended only for promotion. In this context, there is a need for new studies by expanding the study and focusing on the analysis of the content of communication styles with the public, that is, with fellow citizens.

Keywords: Communication, Municipality, New Media, Social Media, Website, Local Governments.

Bu makale intihal tespit yazılımlarıyla taranmıştır. Intihal tespit edilmemiştir.

This article has been scanned by plagiarism detection softwares. No plagiarism detected.

Bu çalışmada "Yükseköğretim Kurumları Bilimsel Araştırma ve Yayın Etiği Yönergesi” kapsamında uyulması belirtilen kurallara uyulmuştur.

In this study, the rules stated in the "Higher Education Institutions Scientific Research and Publication Ethics Directive" were followed.

Yazarların çalışmadaki katkı oranları eşittir.

The authors' contribution rates in the study are equal.

Çalışma kapsamında herhangi bir kurum veya kişi ile çıkar çatışması bulunmamaktadır.

There is no conflict of interest with any institution or person within the scope of the study. 